\title{
Nicotine supplementation enhances simulated game performance of archery athletes
}

\author{
Bao-Lien Hung ${ }^{1}$, Li-Jung Chen², Yi-Ying Chen ${ }^{3}$, Jhih-Bang $\mathrm{Ou}^{3}$ and Shih-Hua Fang ${ }^{3^{*}}$ (D)
}

\begin{abstract}
Background: Nicotine is beneficial to mood, arousal and cognition in humans. Due to the importance of cognitive functioning for archery athletes, we investigated the effects of nicotine supplementation on the cognitive abilities, heart rate variability (HRV), and sport performance of professional archers.

Methods: Eleven college archers were recruited and given $2 \mathrm{mg}$ of nicotine supplementation (NIC group) and placebo (PLA group) in a crossover design.

Results: The results showed that at 30 min after the intake of nicotine gum, the "correct rejection" time in the NIC group was significantly lower than that of the PLA group ( $7.29 \pm 0.87$ vs. $8.23 \pm 0.98 \mathrm{msec}, p<0.05)$. In addition, the NIC group completed the grooved pegboard test in a shorter time than the PLA group (48.76 \pm 3.18 vs. $53.41 \pm$ $4.05 \mathrm{~s}, p<0.05)$, whereas motor reaction times were not different between the two groups. Saliva a-amylase activity was significantly lower after nicotine supplementation $(p<0.01)$ but increased immediately after the archery test in the NIC group $(p<0.05)$. In addition, nicotine supplementation significantly decreased HRV and increased the archery score (290.58 \pm 10.09 vs. $298.05 \pm 8.56, p<0.01)$.
\end{abstract}

Conclusions: Nicotine enhances the performance of archery athletes by increasing cognitive function and stimulating the sympathetic adrenergic system.

Keywords: Nicotine, Cognitive abilities, Archery performance

\section{Introduction}

Athletes, especially in professional team/strength sports (e.g., baseball, ice hockey, wrestling, gymnastics), have different motivations for tobacco consumption, such as enhancing concentration, helping relaxation, allaying fatigue or improving performance [1-4]. However, an association between long-term cigarette smoking and reduced physical performance of athletes has been reported [5]. There is a strong body of evidence related to the harms of tobacco use to lung health from direct and

\footnotetext{
* Correspondence: shfang@ntupes.edu.tw

${ }^{3}$ Institute of Athletics, National Taiwan University of Sport, No. 16, Section 1, Shuang-Shih Road, Taichung 40404, Taiwan

Full list of author information is available at the end of the article
}

passive exposure to tobacco smoke [6]. Pulmonary function was reduced in active smokers in comparison with nonsmokers, especially in skill and power sports [7]. Nicotine, the most abundant alkaloid constituent in tobacco [8], is currently not on the World Anti-Doping Agency (WADA) prohibited list. The use of smokeless tobacco has thus been recommended to obtain the beneficial effects of nicotine and avoid the negative effect of tobacco smoke on the respiratory tract [9].

Nicotine, one of the most widely consumed psychostimulants [10], activates the sympathetic nervous system (SNS) and can increase blood pressure and catecholamine concentrations [11]. Nicotine diffuses readily into the brain and binds to nicotinic cholinergic receptors

(c) The Author(s). 2021 Open Access This article is licensed under a Creative Commons Attribution 4.0 International License, which permits use, sharing, adaptation, distribution and reproduction in any medium or format, as long as you give appropriate credit to the original author(s) and the source, provide a link to the Creative Commons licence, and indicate if changes were made. The images or other third party material in this article are included in the article's Creative Commons. licence, unless indicated otherwise in a credit line to the material. If material is not included in the article's Creative Commons licence and your intended use is not permitted by statutory regulation or exceeds the permitted use, you will need to obtain permission directly from the copyright holder. To view a copy of this licence, visit http://creativecommons.org/licenses/by/4.0/ The Creative Commons Public Domain Dedication waiver (http://creativecommons.org/publicdomain/zero/1.0/) applies to the data made available in this article, unless otherwise stated in a credit line to the data. 
(nAChRs), which are ligand-gated ion channels [12]. A meta-analysis study reported significant positive effects of nicotine in six domains of cognitive function, including fine motor abilities, alerting attention-accuracy and response time (RT), orienting attention-RT, short-term episodic memory-accuracy and working memory-RT [13]. In addition, nicotine enhanced cognitive performance in both smokers and nonsmokers [14]. Moreover, nicotine exhibited promising effects in improving the cognitive functions of patients with pathological diseases such as Parkinson's disease, Alzheimer's disease, schizophrenia and attention-deficit/hyperactivity disorder [15].

Additionally, a systemic review [16] reported that nicotine increased heart rate (HR) in most studies, reflecting an upregulation in sympathetic activity [17], but decreased heart rate variability (HRV), which is an index of autonomic function [18] and is often used as a noninvasive means to assess cardiac autonomic activity in athletic populations $[19,20]$. The low frequency (LF) and high frequency (HF) components of HRV are considered markers of sympathetic and parasympathetic nerve activities [21].

Regarding autonomic regulation, simultaneous and opposite changes in sympathetic and parasympathetic activity of athletes are dependent on several individual and environmental factors, such as training intensity, exercise types and mental stress [22-24]. The regulation of sympathetic and parasympathetic activities is very important for recovery and energy homeostasis during and after exercise in athletes [25]. As another marker of SNS activity, salivary $\alpha$-amylase (sAA) was elevated under physical (e.g., exercise) [26] and psychological (e.g., examination) stress and reflected blood catecholamine levels [27]. Furthermore, a positive correlation between sAA and the LF/HF ratio was reported as a surrogate for sympathetic tone $[28,29]$. Correlations of sAA with anxiety and game records in archery competition have been reported [30]. To supplement HRV data with a neuroendocrinological approach, sAA has attracted much attention as a biomarker of activation of the autonomic nervous system [27].

Based on recent reviews, the effects of nicotine or smoking on physical performance in different types of exercise have not been consistent. Some studies reported ergogenic effects, whereas other studies found unaltered or ergolytic effects $[16,31]$. Recurve archery is an Olympic sport that requires attention, fine movement control, upper body strength and endurance [32, 33]. Nicotine was shown to have a positive effect on attention and facilitate the focus of cognitive responses on a specific task [34, 35]. In addition, nicotine increased skeletal muscle contraction force and delayed fatigue via activation of central cholinergic receptors and peripheral sympathoadrenal effects as an enhancer of power-based sporting performance [31, 36]. Therefore, we hypothesized that nicotine supplementation might be helpful for archery performance.

Several studies have investigated the effects of various dosing forms of nicotine, including transdermal patches, oral smokeless tobacco (snus), oral nicotine gum and inhalers [31]. According to the administration instructions for nicotine gum, one tablet (containing $2 \mathrm{mg}$ of nicotine) is recommended for the first time. Because all the participants recruited in this study were nonsmokers, the reported lowest effective dose of nicotine (i.e., $2 \mathrm{mg}$ ) $[31,37,38]$ was administered. Therefore, the aim of this study was to investigate the effects of 2-mg nicotine gum on cognition, neuroendocrinological responses (HRV and sAA) and archery performance in professional athletes.

\section{Methods \\ Participants}

Eleven healthy, male nonsmokers were recruited in 2018 through printed advertisements and by word of mouth from archery sport teams of both the National Taiwan University of Sport and the National Chung Cheng University in Taiwan. The participants were required to meet the following criteria: (1) they were archers who used a recurve bow; (2) their archery performances were at the national level; and (3) they had been continually training for a minimum of $2 \mathrm{~h} \geq$ three times per week for at least 3 years. Participants were excluded if they had cardiac disease histories, were injured or were unable to participate in normal training $(n=0)$. Therefore, the recruited archers were all qualified and included in this study $(n=11)$. The sample size was calculated by G*power 3.1.9.4 (available at http:// www.gpower.hhu.de). One of our aims was to evaluate the effects of nicotine use on HRV using two-way repeated measures analysis of variance (ANOVA) (within factors). Type 1 error (alpha) was set at the level of $5 \%(p=0.05)$, and the power was set at $80 \%$. The effect size $\mathrm{f}$ was determined by partial eta squared $\left(\eta_{p}{ }^{2}\right)$ based on previous research $\left(\eta_{p}{ }^{2}=0.34\right)$ [31]. The results showed that at least 6 participants were required; thus, the sample size in this study was sufficient. The mean age of the participants was $20.3 \pm 0.3$ years, the mean body weight was $71.1 \pm 9.2$ $\mathrm{kg}$, and the mean body height was $174.4 \pm 4.5 \mathrm{~cm}$. All participants were advised to abstain from stimulants such as coffee or energy drinks for $12 \mathrm{~h}$. Each participant was fully informed of all potential risks and experimental procedures, after which informed written consent was obtained. All experimental procedures and protocols were approved by the Institutional $\mathrm{Hu}$ man Ethics Committee of Jen-Ai Hospital, Taichung, Taiwan. 


\section{Experimental protocol and measures}

The experimental protocol (schematized in Fig. 1) was a randomized, placebo-controlled crossover design, which was conducted across a period of 1 week. On arrival at the laboratory, the participants were fitted with a heartrate strap and monitor (Polar V800, Polar Electro Oy, Kempele, Finland) and seated for $5 \mathrm{~min}$, after which baseline HR measurements were individually taken in stages $1-5$. First, they were asked to remain in the seated position, and saliva samples were collected (stage 1, S1). For experimental trials, the participants chewed 2-mg nicotine gum (NIC group) or flavor-matched placebo gum (PLA group) for $30 \mathrm{~min}$ while seated, followed by the participants' saliva being collected again (stage 2, S2). Then, they completed cognitive tests (Vienna Test System (VTS)-Cognitrone test (COG) and the grooved pegboard test (GPT)) (stage 3, S3) [39]. Furthermore, their archery performance was measured in a simulated game (stage 4, S4). Then, saliva samples were collected (stage 5, S5). Experimental trials were conducted at the same time of day, and the day of and prior to any experimental trial was marked by abstinence from alcohol, any exercise and only habitual caffeine use (as abstinence would in itself have confounding withdrawal-related effects). Additionally, the participants were asked to replicate their diet during the first experimental visit for subsequent trials to ensure a similar metabolic state.

\section{Nicotine intervention}

The participants were instructed to consume the gum according to the manufacturer's recommendations: one piece of 2-mg mint-flavored nicotine gum or placebo gum (Nicorette Icy Mint, Johnson \& Johnson Pacific, Auckland, New Zealand) was introduced into the mouth followed by the instructions "chew until there is a strong taste, then place between your cheek and gums, and chew again when the taste has faded"; this stage lasted for $30 \mathrm{~min}$.

\section{Cognitive function assessments}

All participants completed the cognitive outcome measures including the VTS-Cognitrone test (COG) and grooved pegboard test (GPT). The COG test measures attention and concentration through the comparison of figures regarding their congruence on a computer screen. The participants were presented with an abstract figure, and they were asked to match the figure to a model. The mean time for "correct rejections" made within the total working time of $7 \mathrm{~min}$ was recorded [39]. The GPT is a test of manual dexterity, speed of processing, and hand-eye coordination, which has been used in previous studies $[39,40]$. The GPT includes 25 holes with randomly positioned slots. Participants were asked to put the pegs in the board in a fixed order and in the correct direction with only one hand being used. They were encouraged to perform the task as quickly as possible. The total time to completion was recorded in seconds. In this study, each participant was tested twice with his dominant and nondominant hands. Then, the average time was calculated to give an overall score.

\section{Archery test}

The performance for the archery assessment was assessed according to the rules of national archery competition in outdoor areas. The participants used their own bow and arrow equipment. Before the experiment, they all had adequate warm-up and corrected the sighting position. Briefly, each player fired 72 arrows, 36 arrows for a game. In each single day, they had 2 games. Every participant fired six arrows for a round, and each round time limit was $4 \mathrm{~min}$. Each arrow was worth up to 10 points; therefore, a single game overall had a possible score of 360 points. They rested for $15 \mathrm{~min}$ after the end of the first game. After the end of each round, the arrows were pulled, and the same person recorded the scores to verify the accuracy. Any guidance was excluded during the exercise. The same archery test was performed on three different days in a week to obtain the average archery assessment in each group.

\section{Heart rate variability measurements}

Beat-to-beat heart rate was recorded with 1-ms resolution using portable HR monitors. The HR, percentage of differences between adjacent normal RR intervals of more than $50 \mathrm{~ms}$ (pNN50), low-frequency normalized units (LFnu) and high-frequency normalized units (HFnu) were calculated from the 5-min recordings. LF/ HF was calculated from the ratio of LFnu over HFnu.

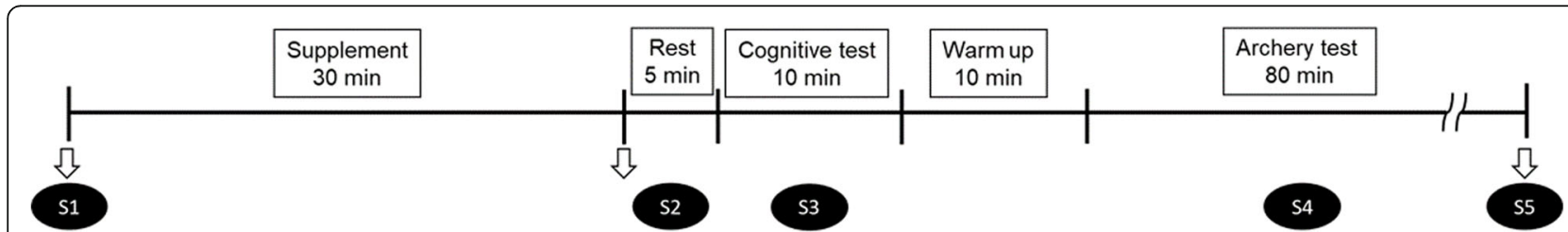

Fig. 1 Graphical representation of the experimental protocol. Stage 1 (S1): before supplementation; S2: after supplementation and before cognitive testing; S3: during cognitive testing; S4: during the archery test; S5: immediately after the archery test. The arrow signs represent the time points when saliva was collected 
Spectral analysis was performed by the maximum entropy method, and autoregressive coefficients were estimated using the Burg algorithm. The power spectrum was calculated from 0.01 to $0.40 \mathrm{~Hz}$ with $0.01-\mathrm{Hz}$ frequency resolution. LF and HF components were calculated through integration of the power spectra of 0.04 to $0.15 \mathrm{~Hz}$ and 0.15 to $0.40 \mathrm{~Hz}$, respectively.

\section{Saliva collection and assay}

Unstimulated whole saliva was collected as previously described [41]. Briefly, all participants were seated and asked to thoroughly rinse their mouth with $30 \mathrm{ml}$ of sterile distilled water before sample collection. The participants remained seated for 10 min until all saliva samples were collected into sterile plastic containers. Two $\mathrm{ml}$ saliva samples were collected at three time points: before gum administration (S1), after gum administration (S2), and after the archery test (S5). The saliva samples were immediately stored at $-80^{\circ} \mathrm{C}$ until assay. Since the half-life of nicotine is short, cotinine, the major metabolite, was used as a reliable marker based on its longer half-life. The salivary cotinine level was determined using an enzyme-linked immunosorbent assay (ELISA) kit (Cozart Bioscience Ltd., Oxfordshire, UK). $\alpha$-Amylase activity was determined using a kinetic reaction assay kit (Salimetrics LLC, State College, PA, USA) according to the manufacturer's instructions. All samples were measured in triplicate. The intra-assay coefficients of variation $(\mathrm{CVs})$ for the measurements of cotinine and $\alpha$ amylase activity were 5 and $4 \%$, respectively.

\section{Statistical analyses}

All data are expressed as the mean \pm standard deviation (SD). Two-way (condition $\mathrm{x}$ time) repeated measures ANOVA with a Tukey post hoc test was used to determine differences between the conditions and time points. Statistical comparisons between the NIC and PLA groups were analyzed using paired t-tests. Partial eta squared $\left(\eta_{p}{ }^{2}\right)$ values are reported as a measure of effect sizes, with demarcations of small $(<0.09)$, medium $(>0.09$ and $<0.25)$ and large $(>0.25)$ effects [31]. Significant differences were set at $p<0.05$.

\section{Results}

All participants completed the study without reporting negative side effects. The mean salivary cotinine level at $30 \mathrm{~min}$ after nicotine supplementation was $10.3 \pm 1.8 \mathrm{ng} /$ $\mathrm{ml}$ and undetectable at S1 and S5.

\section{Effect of nicotine on cognitive and archery performance}

Thirty minutes after chewing the nicotine gum, the participants performed the cognitive function tests. The mean "correct rejection" time in the NIC group was significantly shorter than that in the PLA group (7.29 \pm
0.87 vs. $8.23 \pm 0.98 \mathrm{msec}$, respectively, $p=0.038$; Table 1 ), indicating that the NIC group had better concentration than the PLA group. In addition, the NIC group completed the GPT in a significantly shorter time than the PLA group ( $48.76 \pm 3.18$ vs. $53.41 \pm 4.05$ s, respectively, $p=0.003)$. These findings indicated that the NIC group had better cognitive performance than the PLA group. The participants' archery performance was measured by calculating the mean score of 36 arrows for each game from three independent days. Each arrow was worth up to 10 points. The archery score in the NIC group was significantly higher than that of the PLA group $(298.05 \pm 8.56$ vs. $290.58 \pm 10.09$, respectively, $p=0.009$; Table 1).

\section{Effect of nicotine on heart rate variability}

After supplementation with nicotine (S2), the HR, LF and LF/HF ratio were significantly increased, whereas the pNN50 and HF significantly decreased and were lower than baseline (S1) (Table 2). When the participants were taking the cognitive function test (S3), all the HRV parameters were similar to those at baseline in both groups. During archery performance (S4), the HR, LF and LF/HF ratio were significantly higher, whereas the pNN50 and HF were significantly lower than their own baseline in both groups. In particular, HR in the NIC group was significantly higher than that in the PLA group during the archery test. All HRV parameters in both groups, with the exception of HR in the NIC group returned to baseline after the archery test (S5).

\section{Effect of nicotine on saliva a-amylase activity}

Saliva $\alpha$-amylase activity was significantly decreased $(39.64 \pm 15.97$ vs. $51.82 \pm 19.09 \mathrm{U} / \mathrm{ml}, p<0.01)$ after nicotine supplementation (S2) but increased immediately after the archery test (S5) and was higher than the basal level (S1) $(72.36 \pm 36.66$ vs. $51.82 \pm 19.09 \mathrm{U} / \mathrm{ml}$, respectively, $p<0.05$; Fig. 2 ). At $S 5$, the NIC group showed significantly higher $\alpha$-amylase activity than the PLA group (72.36 \pm 36.66 vs. $50.74 \pm 20.44 \mathrm{U} / \mathrm{ml}$, respectively, $p<$ 0.01 ). There was no difference at the three time points in the PLA group.

\section{Discussion}

To our knowledge, our study was the first to investigate the acute effects of 2-mg nicotine gum supplementation on cognition, HRV, sAA and exercise performance in archery athletes. We found that nicotine supplementation enhanced cognitive function by shortening the time for correct rejection and time on the grooved pegboard test. Second, the HR, LF and LF/HF ratio were increased, whereas the pNN50 and HF were decreased. Third, sAA was increased during the exercise stage. Last, the archery score was significantly increased. The results suggested 
Table 1 Cognitive function and archery performance of each group

\begin{tabular}{|c|c|c|c|c|c|c|c|}
\hline \multirow{2}{*}{$\frac{\text { Parameter }}{\text { Concentration }}$} & \multicolumn{3}{|l|}{ PLA group } & \multicolumn{3}{|c|}{ NIC group } & \multirow{2}{*}{$P$ value } \\
\hline & & & & & & & \\
\hline Mean time "Correct rejection" (msec) & 8.23 & \pm & 0.98 & 7.29 & \pm & $0.87^{\#}$ & 0.038 \\
\hline Speed of processing (sec) & 53.41 & \pm & 4.05 & 48.76 & \pm & $3.18^{\# \#}$ & 0.003 \\
\hline Archery score & 290.58 & \pm & 10.09 & 298.05 & \pm & $8.56^{\# \#}$ & 0.009 \\
\hline
\end{tabular}

Values are presented as the mean \pm SD

$P L A$ group placebo group, NIC group nicotine group

${ }^{\#} p<0.05,{ }^{\# \#} p<0.01$ compared to the PLA group

that there was a positive relationship between nicotine supplementation and archery performance.

In this study, the results showing that nicotine shortened the time for correct rejection and time on the grooved pegboard test were in good agreement with a previous study reporting that the performance of baseball players on math and Stroop tests was better in smokeless tobacco users than nonusers, but smokeless tobacco did not influence psychomotor tasks (choice reaction time and anticipation time) [41]. Consistently, an acute effect of 4-mg nicotine administration (independent of smoking history) was reportedly related to the reaction time on the two-letter search task [42].

Our results demonstrating an increase in the HR, LF and LF/HF ratio were consistent with previous studies reporting that nicotine decreased HRV by stimulating the sympathetic adrenergic system $[43,44]$ and increased HR during submaximal exercise [45], as well as increased LF/HF ratio and HR during training in athletes [46]. sAA was increased immediately after the archery test, which was in good agreement with previous studies reporting that sAA was increased 3 min before and 10 min after archery competition [30] and when sympathetic nerves were activated [47].

Some athletes feel that smokeless tobacco could enhance their performance $[13,41,48]$, but others do not believe so $[49,50]$. That the response to nicotine was significantly heterogeneous among individuals might be due to multiple reasons, including genetic factors, receptor availability, gender, absorption, and performance as well as neural activations at baseline or under placebo [51]. One review [16] identified only two of six studies reporting significant improvements in exercise performance. One study reported that subjects with a 7-mg transdermal nicotine patch given $12 \mathrm{~h}$ prior to a $75 \%$ $\mathrm{VO}_{2} \mathrm{max}$ cycling exercise resulted in an increased

Table $\mathbf{2}$ The heart rate variability in both groups at different stages

\begin{tabular}{|c|c|c|c|c|c|c|c|c|c|c|c|c|}
\hline \multirow[t]{2}{*}{ Outcomes } & \multirow[t]{2}{*}{ Condition } & \multicolumn{5}{|l|}{ Time } & \multicolumn{2}{|c|}{$\begin{array}{l}\text { Condition } \\
\text { effect }\end{array}$} & \multicolumn{2}{|l|}{$\begin{array}{l}\text { Time } \\
\text { effect }\end{array}$} & \multicolumn{2}{|c|}{$\begin{array}{l}\text { Condition } \mathrm{x} \\
\text { Time }\end{array}$} \\
\hline & & S1 & S2 & S3 & S4 & S5 & $p$ & $n_{p}^{2}$ & $p$ & $\eta_{p}^{2}$ & $p$ & $\eta_{p}^{2}$ \\
\hline \multirow[t]{3}{*}{ HR (bpm) } & & & & & & & .028 & .474 & $<.001$ & .815 & .039 & .319 \\
\hline & PLA & $82.23 \pm 6.50$ & $82.50 \pm 6.83$ & $79.75 \pm 5.96$ & $95.41 \pm 5.33^{\text {aaa }}$ & $81.72 \pm 6.85$ & & & & & & \\
\hline & $\mathrm{NIC}$ & $79.51 \pm 5.15$ & $84.49 \pm 6.85^{a}$ & $84.24 \pm 8.14$ & $101.70 \pm 8.04^{\text {aaa, \#\# }}$ & $87.85 \pm 9.53^{\mathrm{a}}$ & & & & & & \\
\hline \multirow[t]{3}{*}{ pNN50 (\%) } & & & & & & & .229 & .175 & $<.001$ & .562 & .023 & 290 \\
\hline & PLA & $14.16 \pm 7.83$ & $13.26 \pm 9.94$ & $18.37 \pm 10.05$ & $5.56 \pm 3.63^{\mathrm{aa}}$ & $17.03 \pm 9.56$ & & & & & & \\
\hline & $\mathrm{NIC}$ & $18.86 \pm 9.94$ & $8.77 \pm 5.16^{\mathrm{aa}}$ & $13.08 \pm 6.40$ & $5.25 \pm 2.82^{\text {aа }}$ & $12.21 \pm 8.21$ & & & & & & \\
\hline \multirow[t]{3}{*}{ LF(n.u.) } & & & & & & & .371 & .081 & .008 & .396 & .588 & .067 \\
\hline & PLA & $68.30 \pm 7.22$ & $69.41 \pm 7.55$ & $64.62 \pm 8.00$ & $77.39 \pm 12.74^{a}$ & $61.63 \pm 11.14^{\mathrm{a}}$ & & & & & & \\
\hline & $\mathrm{NIC}$ & $65.56 \pm 12.90$ & $72.01 \pm 8.11^{\mathrm{a}}$ & $68.33 \pm 9.10$ & $77.52 \pm 10.05^{\text {aа }}$ & $65.35 \pm 10.56$ & & & & & & \\
\hline \multirow[t]{3}{*}{ HF(n.u.) } & & & & & & & .371 & .081 & .008 & .396 & .588 & .067 \\
\hline & PLA & $31.70 \pm 7.22$ & $30.59 \pm 7.55$ & $35.38 \pm 8.00$ & $22.61 \pm 12.74^{\mathrm{a}}$ & $38.37 \pm 11.14^{a}$ & & & & & & \\
\hline & $\mathrm{NIC}$ & $34.44 \pm 12.90$ & $27.99 \pm 8.11^{\mathrm{a}}$ & $31.67 \pm 9.10$ & $22.48 \pm 10.05^{\mathrm{aa}}$ & $34.65 \pm 10.56$ & & & & & & \\
\hline \multirow[t]{3}{*}{ LF/HF } & & & & & & & .655 & .021 & .002 & .565 & .516 & .065 \\
\hline & PLA & $2.44 \pm 0.75$ & $2.61 \pm 0.81$ & $2.14 \pm 0.91$ & $5.28 \pm 3.31^{a}$ & $2.02 \pm 1.00$ & & & & & & \\
\hline & $\mathrm{NIC}$ & $2.26 \pm 0.98$ & $3.15 \pm 1.17^{\mathrm{a}}$ & $2.70 \pm 1.58$ & $4.73 \pm 2.04^{\mathrm{aa}}$ & $2.33 \pm 0.83$ & & & & & & \\
\hline
\end{tabular}

Values are presented as the mean $\pm S D$

$\eta_{p}^{2}$ Partial eta squared

${ }^{a} p<0.05$, aa $p<0.01$, aaa $p<0.001$ compared to $\mathrm{S} 1$ in each group

$\#$ \#\# 0.01 compared to the PLA group 


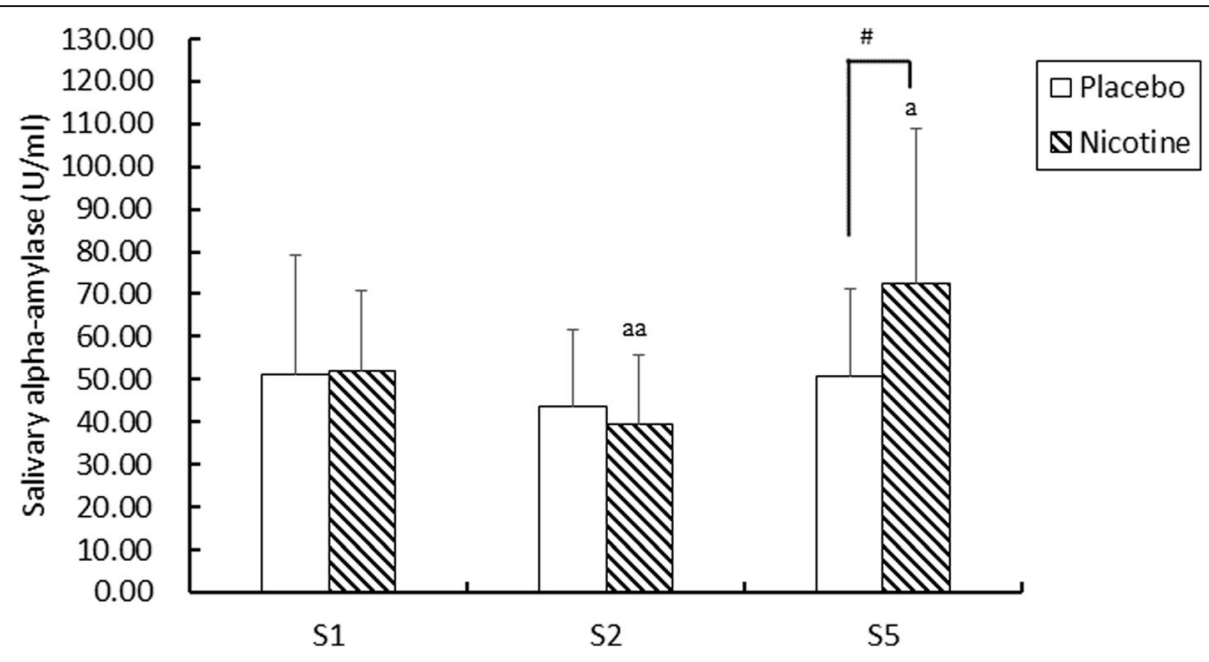

Fig. 2 Salivary a-amylase activity in Stage 1 (S1), S2 and S5. Values are presented as the mean \pm SD. Stage 1 (S1): before supplementation; S2: after supplementation and before cognitive testing; S5: immediately after the archery test. a: $p<0.05$; aa: $p<0.01$ compared to S1 in each group, \#: $p<0.01$, compared to the placebo group

exercise time by $17 \pm 7 \%$ [52] but no effect on the rate of perceived exertion. Another study reported in healthy team sports members who had never smoked that chewing 2-mg nicotine gum 20 min prior to exercise caused higher HR and increased leg extensor force but did not affect countermovement jump height or Wingate anaerobic capacity [31]. In addition, a recent study demonstrated that 5-mg nicotine strip administration increased repeated anaerobic performance in peak power and average power in nicotine-naïve athletes [53]. This result indicated that the probable mechanism of nicotine might be through activation of the SNS and increasing heart rate as well as blood pressure [53]. After $12 \mathrm{~h}$ of overnight nicotine abstinence, snus (approximately $8 \mathrm{mg}$ nicotine) induced an increase in time to exhaustion in a $80 \% \mathrm{VO}_{2}$ max exercise test [54]. In addition, the muscular and cerebral oxygenation in nontobacco users increased with snus (8 $\mathrm{mg}$ nicotine) administration in a $65 \%$ of the maximal aerobic power output exercise until exhaustion test, but fatigue perception and time to exhaustion were not affected [55].

In this study, archery scores were significantly increased by nicotine supplementation. Archery demands very specific muscle strength, endurance fitness, and hand-eye coordination for successful intermittent repetitive shooting performance $[56,57]$. All these characteristics of archers are modulated by the autonomic nervous system [58]. A previous study demonstrated that 6-mg nicotine gum enhanced visuospatial selective attention with regard to early visual encoding and analysis in nonsmokers [59]. In addition, 2-mg nicotine gum reduced movement times, increased velocities and resulted in more fluent handwriting movements in nondeprived smokers and smokers [38], and increased cutaneous blood flow and skin temperature [37]. Furthermore, a study demonstrated that intravenous injections of 0.4 to $1 \mathrm{mg}$ of nicotine to nonsmokers caused an increase in blood flow in muscle [60]. Taken together, increased blood flow to supply adequate oxygen to active skeletal muscle might be one of the reasons explaining the enhanced archery performance.

The athletes believed that consumption of nicotine/ nicotine-containing substances proved ergogenic through augmenting saliva secretion, stimulating satiety, improving reaction time and concentration, helping relaxation and producing desirable arousal and attention $[49,61]$. In relation to the archery performance test, we monitored autonomic assessment for the spectral analysis of HRV and sAA activity. Based on our results, we suggest that nicotine might help athletes maintain concentration and sympathetic activation, thereby improving sport performance. However, our study has several limitations. First, because of the limited number of male national-level archery athletes using the recurve bow, the sample size of this study was small. Whether similar effects would occur with other types of exercise needs more investigation. Second, we did not monitor female archers or archers who were smokers. It is unclear whether our findings regarding the acute effects of nicotine can be applied to other populations. Additionally, both the pharmacokinetics and pharmacodynamics of nicotine can differ between smokers and nonsmokers. Third, we used a single, low dose of nicotine in this study. Therefore, the dose-dependent effect of nicotine on exercise performance needs further study. Moreover, if athletes use nicotine too often, it is necessary to examine whether there is a decrease in the ergogenic effect as has been seen with caffeine use. 
Tobacco use is highly addictive and a major risk factor for cardiovascular and respiratory diseases, over 20 different types or subtypes of cancer, and many other debilitating health conditions. More than 8 million people die from tobacco use each year [62]. Previous studies have indicated that nicotine exhibits dose-dependent bidirectional regulation of mouse [63] and rat [64] stem cell proliferation. Moreover, long-term and/or continuous nicotine administration has been reported to have a deleterious effect on ischemic brain injury [65]. Since nicotine has the potential to be additive, there is a possibility that athletes who are nonusers of tobacco may become addicted. Previous studies using questionnaires showed that nicotine gum is less addictive than tobacco cigarettes [66], and addiction to nicotine gum in neversmokers is probably quite rare [67]. In addition, the use of 2-mg nicotine gum as nicotine replacement therapy for 5 years appeared to be safe and to not cause cancer $[68,69]$. However, the usage of nicotine still needs to be carefully considered because it is a psychoactive and addictive substance with effects in the brain. In the future, there is a need for more research examining the effects of different dosages of nicotine on cognitive functions, HR, LF and LF/HF ratios between smokers and nonsmokers to evaluate nicotine as a potential ergogenic aid for different sports.

\section{Conclusions}

In summary, these results indicated that 2-mg nicotine gum supplementation enhanced cognitive function, decreased saliva $\alpha$-amylase activity and HRV through stimulating the sympathetic adrenergic system. More importantly, the archery scores were significantly increased after nicotine supplementation.

\footnotetext{
Abbreviations

HRV: Heart rate variability; NIC: Nicotine; PLA: Placebo; WADA: World AntiDoping Agency; SNS: Sympathetic nervous system; nAChRs: nicotinic cholinergic receptors; RT: Response time; HR: Heart rate; LF: Low frequency; HF: High frequency; sAA: salivary a-amylase; ANOVA: Analysis of variance; VTS: Vienna Test System; COG: Cognitrone test; GPT: Grooved pegboard test; pNN50: percentage of differences between adjacent normal heart rate intervals of more than 50 ms; LFnu: Low-frequency normalized units; HFnu: High-frequency normalized units; CV: Coefficient of variation; SD: Standard deviation
}

\section{Acknowledgments}

The authors heartily thank coach Chien-Nan Liao, coach Ming-Huang Liu, and all the participants without whom this study would not have been possible.

\section{Authors' contributions}

B.L.H., L.J.C., and S.H.F. were responsible for the conception and design of the experiment. B.L.H. wrote the first draft of the manuscript. B.L.H., L.J.C., Y.Y.C., J.B.O., and S.H.F. were involved in different aspects of data collection, data analysis and interpretation. All authors read and approved the final manuscript.

\section{Funding}

We thank the Taiwan Ministry of Science and Technology (MOST104-2628$\mathrm{H}-028-001-\mathrm{MY} 2)$ for funding the research.

\section{Availability of data and materials}

The datasets used and/or analyzed during the current study are available from the corresponding author on reasonable request.

\section{Ethics approval and consent to participate}

Participants were informed of the risks and benefits of participating and provided written informed consent before participating in the study. This study was approved by the Institutional Human Ethics Committee of Jen-Ai Hospital (\#105-24), Taichung, Taiwan.

\section{Consent for publication}

Not applicable.

\section{Competing interests}

The authors declare that they have no competing interests.

\section{Author details}

'Department of Sports Medicine, China Medical University, Taichung 40402, Taiwan. ${ }^{2}$ Department of Exercise Health Science, National Taiwan University of Sport, Taichung 40404, Taiwan. ${ }^{3}$ Institute of Athletics, National Taiwan University of Sport, No. 16, Section 1, Shuang-Shih Road, Taichung 40404, Taiwan.

Received: 30 March 2020 Accepted: 9 February 2021

Published online: 18 February 2021

\section{References}

1. Severson HH, Klein K, Lichtensein E, Kaufman N, Orleans CT. Smokeless tobacco use among professional baseball players: survey results, 1998 to 2003. Tob Control. 2005;14(1):31-6.

2. Mattila VM, Raisamo S, Pihlajamaki H, Mantysaari M, Rimpela A. Sports activity and the use of cigarettes and snus among young males in Finland in 1999-2010. BMC Public Health. 2012;12:230.

3. Alaranta A, Alaranta H, Patja K, Palmu P, Prattala R, Martelin T, Helenius I. Snuff use and smoking in Finnish olympic athletes. Int J Sports Med. 2006; 27(7):581-6.

4. Henninger S, Fischer R, Cornuz J, Studer J, Gmel G. Physical activity and snus: is there a link? Int J Environ Res Public Health. 2015;12(7):7185-98.

5. Mendonca GV, Pereira FD, Fernhall B. Effects of cigarette smoking on cardiac autonomic function during dynamic exercise. J Sports Sci. 2011; 29(9):879-86

6. St Claire S, Gouda H, Schotte K, Fayokun R, Fu D, Varghese C, Prasad VM. Lung health, tobacco, and related products: gaps, challenges, new threats, and suggested research. Am J Physiol Lung Cell Mol Physiol. 2020;318(5): L1004-7.

7. Saranovic SD, Vicic J, Pesic I, Tomovic M, Batinic D, Antic M, Tadic M, Mazic $S$. The influence of tobacco use on pulmonary function in elite athletes. Int J Environ Res Public Health. 2019;16(19):3515.

8. Benowitz NL, Gourlay SG. Cardiovascular toxicity of nicotine: implications for nicotine replacement therapy. J Am Coll Cardiol. 1997;29(7):1422-31.

9. Chague F, Guenancia C, Gudjoncik A, Moreau D, Cottin Y, Zeller M. Smokeless tobacco, sport and the heart. Arch Cardiovasc Dis. 2015;108(1): 75-83.

10. Boutrel B, Koob GF. What keeps us awake: the neuropharmacology of stimulants and wakefulness-promoting medications. Sleep. 2004;27(6):118194.

11. Haass M, Kubler W. Nicotine and sympathetic neurotransmission. Cardiovasc Drugs Ther. 1997;10(6):657-65.

12. Graef S, Schonknecht P, Sabri O, Hegerl U. Cholinergic receptor subtypes and their role in cognition, emotion, and vigilance control: an overview of preclinical and clinical findings. Psychopharmacology. 2011;215(2):205-29.

13. Heishman SJ, Kleykamp BA, Singleton EG. Meta-analysis of the acute effects of nicotine and smoking on human performance. Psychopharmacology. 2010;210(4):453-69.

14. Herman Al, Sofuoglu M. Cognitive effects of nicotine: genetic moderators. Addict Biol. 2010;15(3):250-65. 
15. Newhouse PA, Potter A, Singh A. Effects of nicotinic stimulation on cognitive performance. Curr Opin Pharmacol. 2004;4(1):36-46.

16. Johnston R, Doma K, Crowe M. Nicotine effects on exercise performance and physiological responses in nicotine-naïve individuals: a systematic review. Clin Physiol Funct Imaging. 2018;38(4):527-38.

17. Daanen HA, Lamberts RP, Kallen VL, Jin A, Van Meeteren NL. A systematic review on heart-rate recovery to monitor changes in training status in athletes. Int J Sports Physiol Perform. 2012;7(3):251-60.

18. Bigger JT Jr, Fleiss JL, Steinman RC, Rolnitzky LM, Schneider WJ, Stein PK. RR variability in healthy, middle-aged persons compared with patients with chronic coronary heart disease or recent acute myocardial infarction. Circulation. 1995;91(7):1936-43.

19. Edmonds $\mathrm{RC}$, Sinclair WH, Leicht AS. Effect of a training week on heart rate variability in elite youth rugby league players. Int J Sports Med. 2013;34(12): 1087-92.

20. Buchheit M, Simpson MB, Al Haddad H, Bourdon PC, Mendez-Villanueva A. Monitoring changes in physical performance with heart rate measures in young soccer players. Eur J Appl Physiol. 2012;112(2):711-23.

21. Camm AJ, Malik M, Bigger JT, Breithardt G, Cerutti S, Cohen RJ, Coumel P, Fallen EL, Kennedy HL, Kleiger RE, et al. Heart rate variability: standards of measurement, physiological interpretation and clinical use. Task force of the European Society of Cardiology and the north American Society of Pacing and Electrophysiology. Circulation. 1996;93(5):1043-65.

22. Botek M, McKune AJ, Krejci J, Stejskal P, Gaba A. Change in performance in response to training load adjustment based on autonomic activity. Int J Sports Med. 2014;35(6):482-8.

23. Kiss O, Sydo N, Vargha P, Vago H, Czimbalmos C, Edes E, Zima E, Apponyi G, Merkely G, Sydo T, Becker D, Allison T, Merkely B. Detailed heart rate variability analysis in athletes. Clin Auton Res. 2016;26(4):245-52.

24. Oliveira RS, Leicht AS, Bishop D, Barbero-Alvarez JC, Nakamura FY. Seasonal changes in physical performance and heart rate variability in high level futsal players. Int J Sports Med. 2013;34(5):424-30.

25. lellamo F, Lucini D, Volterrani M, Casasco M, Salvati A, Gianfelici A, Di Gianfrancesco A, Urso A, Manzi V. Autonomic nervous system responses to strength training in top-level weight lifters. Physiol Rep. 2019;7(20):e14233.

26. Koibuchi E, Suzuki Y. Exercise upregulates salivary amylase in humans (review). Exp Ther Med. 2014;7(4):773-7.

27. Chatterton RT Jr, Vogelsong KM, Lu YC, Ellman AB, Hudgens GA. Salivary alpha-amylase as a measure of endogenous adrenergic activity. Clin Physiol. 1996;16(4):433-48

28. Filaire E, Portier $H$, Massart A, Ramat L, Teixeira A. Effect of lecturing to 200 students on heart rate variability and alpha-amylase activity. Eur J Appl Physiol. 2010;108(5):1035-43.

29. Nater UM, La Marca R, Florin L, Moses A, Langhans W, Koller MM, Ehlert U. Stress-induced changes in human salivary alpha-amylase activity -- associations with adrenergic activity. Psychoneuroendocrinology. 2006;31(1):49-58.

30. Lim IS. Correlation between salivary alpha-amylase, anxiety, and game records in the archery competition. J Exerc Nutr Biochem. 2016;20(4):44-7.

31. Mundel T, Machal M, Cochrane DJ, Barnes MJ. A randomised, placebocontrolled, crossover study investigating the effects of nicotine gum on strength, power and anaerobic performance in nicotine-naive, active males. Sports Med Open. 2017;3(1):5.

32. Mononen K, Konttinen N, Viitasalo J, Era P. Relationships between postural balance, rifle stability and shooting accuracy among novice rifle shooters. Scand J Med Sci Sports. 2007;17(2):180-5.

33. Spratford W, Campbell R. Postural stability, clicker reaction time and bow draw force predict performance in elite recurve archery. Eur J Sport Sci. 2017;17(5):539-45

34. Lawrence NS, Ross TJ, Stein EA. Cognitive mechanisms of nicotine on visual attention. Neuron. 2002;36(3):539-48.

35. Mansvelder HD, van Aerde Kl, Couey JJ, Brussaard AB. Nicotinic modulation of neuronal networks: from receptors to cognition. Psychopharmacology. 2006;184(3-4):292-305.

36. Andersson DC, Betzenhauser MJ, Reiken S, Umanskaya A, Shiomi T, Marks AR. Stress-induced increase in skeletal muscle force requires protein kinase a phosphorylation of the ryanodine receptor. J Physiol. 2012;590(24):6381-7.

37. Usuki K, Kanekura T, Aradono K, Kanzaki T. Effects of nicotine on peripheral cutaneous blood flow and skin temperature. J Dermatol Sci. 1998;16(3):173-81.

38. Tucha $\mathrm{O}$, Lange KW. Effects of nicotine chewing gum on a real-life motor task: a kinematic analysis of handwriting movements in smokers and nonsmokers. Psychopharmacology. 2004;173(1-2):49-56.
39. Stubbs B, Ku PW, Chung MS, Chen LJ. Relationship between objectively measured sedentary behavior and cognitive performance in patients with schizophrenia vs controls. Schizophr Bull. 2017;43(3):566-74.

40. Li CY, Hsu GS, Suzuki K, Ko MH, Fang SH. Salivary immuno factors, cortisol and testosterone responses in athletes of a competitive $5,000 \mathrm{~m}$ race. Chin J Physiol. 2015;58(4):263-9.

41. Landers DM, Crews DJ, Boutcher SH, Skinner JS, Gustafsen S. The effects of smokeless tobacco on performance and psychophysiological response. Med Sci Sports Exerc. 1992;24(8):895-903.

42. Ernst M, Heishman SJ, Spurgeon L, London ED. Smoking history and nicotine effects on cognitive performance. Neuropsychopharmacology. 2001;25(3):313-9.

43. Morente-Sanchez J, Zandonai T, Mateo-March M, Sanabria D, SanchezMunoz C, Chiamulera C, Zabala DM. Acute effect of Snus on physical performance and perceived cognitive load on amateur footballers. Scand J Med Sci Sports. 2015;25(4):e423-31.

44. Harte CB, Meston CM. Acute effects of nicotine on physiological and subjective sexual arousal in nonsmoking men: a randomized, double-blind, placebo-controlled trial. J Sex Med. 2008;5(1):110-21.

45. Van Duser BL, Raven PB. The effects of oral smokeless tobacco on the cardiorespiratory response to exercise. Med Sci Sports Exerc. 1992;24(3):389-95.

46. Druyan A, Atias D, Ketko I, Cohen-Sivan Y, Heled Y. The effects of smoking and nicotine ingestion on exercise heat tolerance. J Basic Clin Physiol Pharmacol. 2017;28(2):167-70.

47. Gordis EB, Granger DA, Susman EJ, Trickett PK. Asymmetry between salivary cortisol and alpha-amylase reactivity to stress: relation to aggressive behavior in adolescents. Psychoneuroendocrinology. 2006;31(8):976-87.

48. Pesta DH, Angadi SS, Burtscher M, Roberts CK. The effects of caffeine, nicotine, ethanol, and tetrahydrocannabinol on exercise performance. Nutr Metab (Lond). 2013;10(1):71.

49. Connolly GN, Orleans CT, Kogan M. Use of smokeless tobacco in majorleague baseball. N Engl J Med. 1988;318(19):1281-5.

50. Edwards SW, Glover ED, Schroeder KL. The effects of smokeless tobacco on heart rate and neuromuscular reactivity in athletes and nonathletes. Phys Sportsmed. 1987;15(7):141-7.

51. Perkins KA. Baseline-dependency of nicotine effects: a review. Behav Pharmacol. 1999;10(6-7):597-615.

52. Mundel $\mathrm{T}$, Jones DA. Effect of transdermal nicotine administration on exercise endurance in men. Exp Physiol. 2006;91(4):705-13.

53. Johnston $\mathrm{R}$, Crowe M, Doma K. Effect of nicotine on repeated bouts of anaerobic exercise in nicotine naive individuals. Eur J Appl Physiol. 2018; 118(4):681-9.

54. Zandonai T, Tam E, Bruseghini P, Capelli C, Baraldo M, Chiamulera C. Exercise performance increase in smokeless tobacco-user athletes after overnight nicotine abstinence. Scand J Med Sci Sports. 2019;29(3):430-9.

55. Zandonai T, Tam E, Bruseghini P, Pizzolato F, Franceschi L, Baraldo M, Capelli C, Cesari $P$, Chiamulera $C$. The effects of oral smokeless tobacco administration on endurance performance. J Sport Health Sci. 2018;7(4):465-72.

56. Chang Y, Lee JJ, Seo JH, Song HJ, Kim YT, Lee HJ, Kim HJ, Lee J, Kim W, Woo M, Kim JG. Neural correlates of motor imagery for elite archers. NMR Biomed. 2011;24(4):366-72.

57. Kim W, Chang Y, Kim J, Seo J, Ryu K, Lee E, Woo M, Janelle CM. An fMRI study of differences in brain activity among elite, expert, and novice archers at the moment of optimal aiming. Cogn Behav Neurol. 2014;27(4):173-82.

58. Carrillo AE, Christodoulou VX, Koutedakis Y, Flouris AD. Autonomic nervous system modulation during an archery competition in novice and experienced adolescent archers. J Sports Sci. 2011;29(9):913-7.

59. Impey D, Chique-Alfonzo M, Shah D, Fisher D, Knott V. Effects of nicotine on visuospatial attentional orienting in non-smokers. Pharmacol Biochem Behav. 2013;106:1-7.

60. Rottenstein $H$, Peirce $G$, Russ E, Felder D, Montgomery H. Influence of nicotine on the blood flow of resting skeletal muscle and of the digits in normal subjects. Ann N Y Acad Sci. 1960;90:102-13.

61. Glover ED, Edmundson EW, Edwards SW, Schroeder KL. Implications of smokeless tobacco use among athletes. Phys Sportsmed. 1986;14(12):95-105.

62. World Health Organization. Tobacco. 2020 https://www.who.int/healthtopics/tobacco\#tab=tab_1. Accessed 29 Sept 2020.

63. Qu Q, Zhang F, Zhang X, Yin W. Bidirectional regulation of mouse embryonic stem cell proliferation by nicotine is mediated through Wnt signaling pathway. Dose-Response. 2017;15(4):1559325817739760. 
64. Shi Z, Wang Q, Jiang D. Ascorbic acid mitigates the deleterious effects of nicotine on tendon stem cells. Connect Tissue Res. 2019:1-11.

65. Katsuki H, Matsumoto K. Nicotinic acetylcholine receptors in regulation of pathology of cerebrovascular disorders. In: Akaike A, Shimohama S, Misu Y, editors. Nicotinic Acetylcholine Receptor Signaling in Neuroprotection. Singapore: Drug and Alcohol Dependence; 2018. p. 113-36. https://www. ncbi.nlm.nih.gov/pmc/articles/PMC4920051/.

66. Etter JF, Eissenberg T. Dependence levels in users of electronic cigarettes, nicotine gums and tobacco cigarettes. Drug Alcohol Depend. 2015;147:68-75.

67. Etter JF. Addiction to the nicotine gum in never smokers. BMC Public Health. 2007:7:159.

68. Murray RP, Bailey WC, Daniels K, Bjornson WM, Kurnow K, Connett JE, Nides MA, Kiley JP. Safety of nicotine polacrilex gum used by 3,094 participants in the lung health study. Lung Health Study Research Group. Chest. 1996; 109(2):438-45.

69. Murray RP, Connett JE, Zapawa LM. Does nicotine replacement therapy cause cancer? Evidence from the lung health study. Nicotine Tob Res. 2009; 11(9):1076-82.

\section{Publisher's Note}

Springer Nature remains neutral with regard to jurisdictional claims in published maps and institutional affiliations.

Ready to submit your research? Choose BMC and benefit from:

- fast, convenient online submission

- thorough peer review by experienced researchers in your field

- rapid publication on acceptance

- support for research data, including large and complex data types

- gold Open Access which fosters wider collaboration and increased citations

- maximum visibility for your research: over $100 \mathrm{M}$ website views per year

At BMC, research is always in progress.

Learn more biomedcentral.com/submissions 